\title{
Natural Polymer of Iraqi Apricot Tree Gum as a Novel Corrosion Inhibitor for Mild Steel in 1 M HCl Solution
}

\author{
I. M. Alwaan and Fouad Kadhim Mahdi \\ Department of Materials Engineering, College of Engineering, University of Kufa, Najaf, Iraq \\ Correspondence should be addressed to I. M. Alwaan; ism10alw@yahoo.com
}

Received 29 December 2015; Revised 24 March 2016; Accepted 5 April 2016

Academic Editor: Xijun $\mathrm{Hu}$

Copyright (C) 2016 I. M. Alwaan and F. K. Mahdi. This is an open access article distributed under the Creative Commons Attribution License, which permits unrestricted use, distribution, and reproduction in any medium, provided the original work is properly cited.

Corrosion inhibition of mild steel in $1 \mathrm{M}$ hydrochloric acid using Iraqi apricot tree gum Arabic as natural polymer was studied. The weight loss method was used to predict the efficiency of the inhibitor on corrosion of mild steel in a temperature range of $17-40^{\circ} \mathrm{C}$. The FTIR result of natural polymer revealed that the $\mathrm{C}=\mathrm{O}$ and $\mathrm{O}-\mathrm{H}$ groups were found in the structure of the natural polymer. The results of weight loss method showed that the inhibition efficiency (I\%) increased with the increase in both the natural polymer concentration and the temperature; therefore, chemical adsorption mechanism was suggested in this system. The different mathematical models of the adsorption isotherms were studied and the results revealed that natural polymer was found to obey Temkin, Langmuir, and Freundlich adsorption isotherm. The activation energy of adsorption, enthalpy of adsorption, and entropy of adsorption were obtained for different concentrations of natural polymer $(0,0.1,0.2$, and $0.3 \mathrm{~g} / \mathrm{L})$ and the results showed that the thermodynamic properties decreased with the loading of a natural polymer. Gibbs free energy of adsorption results was a minus value that led to the conclusion of the spontaneous adsorption of the natural polymer in this system.

\section{Introduction}

Mild steel has been widely utilized in chemical industry equipment and the corrosive materials such as alkalis, acids, and salt solutions are contacted with mild steel materials. Hydrochloric acid and sulfuric acid are utilized a lot in acid cleaning, pickling, and acidizing in mining and oil wells. Moreover, they are mostly utilized for the removal of undesirable scale and rust in several industrial operations [1].

Most of the acid inhibitors are organic materials with N, S, and $\mathrm{O}$ atoms and various bonds in their structure. In addition, many N-heterocyclic compounds have been reported as effective inhibitors for metals corrosion and alloys in aqueous media [2-7]. The absorption of inhibitors on metal surfaces leads to coverage of active sites of metal surface and thereby leads to a decrease in the metal corrosion rate. Moreover, the metal kind and metal face charge, the chemical construction of organic controllers, and the electron distribution in the molecule are impact factors in the operation of inhibitor adsorption [2].
Natural inhibitors substances are more attractive than synthesized organic inhibitors because they are environmentally friendly, nontoxic, cheap, and readily available and are a renewable source of materials. The natural products such as natural honey [8,9], henna [10], opuntia extract [11], guar gum [12], jojoba oil [13], Artemisia oil [14], and Telfairia occidentalis extract [15] have been studied as corrosion inhibitors for iron and steel materials in acidic media.

The present work was designed to study the corrosion inhibition of mild steel in $1 \mathrm{M} \mathrm{HCl}$ solution by gum Arabic of Iraqi apricot tree as a natural polymer (GA) as corrosion inhibitor using weight loss technique. Moreover, the effect of temperature in the range of $17-40^{\circ} \mathrm{C}$ on corrosion behavior was studied in the presence and absence of inhibitor. To the best of our knowledge, there has not been any systematic investigation on the influence of gum Arabic of Iraqi apricot tree on the corrosion of mild steel in $1 \mathrm{M} \mathrm{HCl}$ solution.

\section{Experimental}

2.1. Materials, Solution Preparation, and Method. The dimension of metal specimens was $1.6 \times 2 \times 0.08 \mathrm{~cm}$. These pieces 
TABLE 1: The mild steel alloy components (wt.\%).

\begin{tabular}{lcccccccccccc}
\hline Elements & $\mathrm{C}$ & $\mathrm{Si}$ & $\mathrm{Mn}$ & $\mathrm{P}$ & $\mathrm{S}$ & $\mathrm{Cr}$ & $\mathrm{Mo}$ & $\mathrm{Cu}$ & $\mathrm{Ni}$ & $\mathrm{Co}$ & $\mathrm{Fe}$ \\
\hline Composition & 0.086 & 0.319 & 8.29 & 0.053 & 0.019 & 14.0 & 0.012 & 1.62 & 0.985 & 0.083 & $\mathrm{Bal}$ \\
\hline
\end{tabular}

were used without further polishing. The specimens were cleaned of grease using absolute ethanol and were dried in acetone, and then the specimens were kept in desiccators to avoid the humidity effect until they were utilized in the study of corrosion. The mild steel alloy components are shown in Table 1.

The hydrochloric acid solution at the concentration of $1 \mathrm{M}$ was prepared by dilution of 37 weight $\% \mathrm{HCl}$ using bidistilled water. The GA is a natural product and was collected from Iraqi apricot trees. The solutions of GA were prepared by dissolving the GA in $1 \mathrm{M} \mathrm{HCl}$ acid solution at given concentration. The samples were curing in GA solutions after the GA material completely dissolved in $1 \mathrm{M} \mathrm{HCl}$ acid solution. Moreover, the precleaned mild steel coupons were hanged in $100 \mathrm{~mL}$ of $\mathrm{HCl}(1 \mathrm{M})$ solutions at a temperature range of $17-40^{\circ} \mathrm{C}$. After finishing a period of curing time, the weight loss was located by scrubbing the specimens using a bristle brush under running water in order to remove the corrosion product, followed by drying and weighing. The difference between the weight at a given time and the original weight of the coupons represented the weight loss of specimens. The calculations were achieved by employing LP 120 electronic balance with a sensibility of $\pm 0.0001 \mathrm{~g}$. The results depended on triplicate assessment and the average value of the weight loss is stated.

The corrosion rate of mild steel has been calculated for a 5-hour immersion period in different concentrations of the inhibitor and the weight loss method was dependent on calculating the corrosion rate (CR) as follows:

$$
\mathrm{CR}\left(\mathrm{mg} \mathrm{cm}^{-2} \mathrm{~h}^{-1}\right) r=\frac{\Delta W}{A \cdot t}
$$

where $\Delta W$ is the corrosion weight loss of mild steel (mg) while $A$ and $t$ are the area of the specimen $\left(\mathrm{cm}^{2}\right)$ and the exposure time (h), respectively.

The inhibition efficiencies of inhibitors were calculated on a percentage basis as follows:

$$
I \%=\frac{W_{o}-W_{1}}{W_{o}}
$$

where $W_{o}$ is the weight loss value in the absence of inhibitor and $W_{1}$ is the weight loss value in the presence of inhibitor.

\subsection{Fourier Transform Infrared (FTIR) Spectroscopy. Fourier} transform infrared (FTIR) spectroscopy was used to investigate the chemical structure of GA. IR sample spectrum was conducted using a Shimadzu spectrophotometer. The range of measurements was 4000 to $400 \mathrm{~cm}^{-1}$ at atmospheric temperature while the resolution was preserved at $16 \mathrm{~cm}^{-1}$.

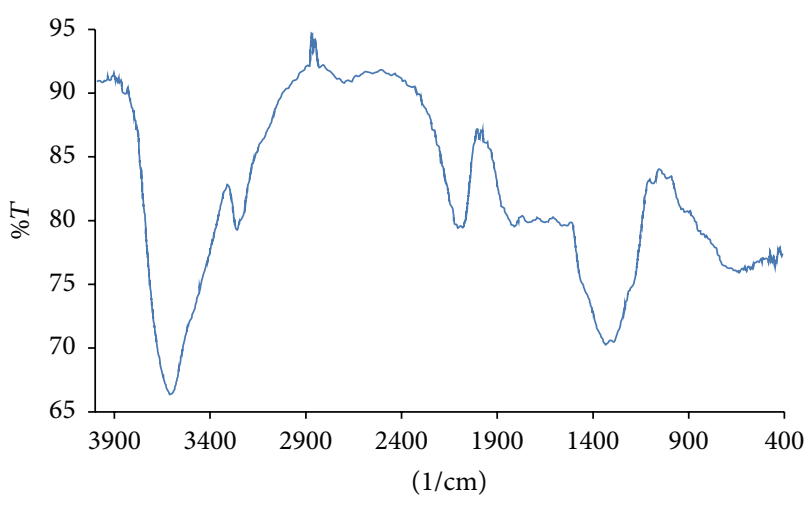

FIGURE 1: FTIR spectra of GA.

\section{Results and Discussion}

3.1. Fourier Transform Infrared (FTIR) Spectroscopy. Figure 1 shows the FTIR spectra of gum Arabic of Iraqi apricot tree as a natural polymer (GA). The spectrum of FTIR exhibits clearly strong peaks at the absorption bands of 1100, 1650, 2960, and $3400 \mathrm{~cm}^{-1}$. The stretching vibrations of the $\mathrm{O}-\mathrm{H}$ bond appear at $3400 \mathrm{~cm}^{-1}$ with the strong peak at $1650 \mathrm{~cm}^{-1}$ due to the stretching vibrations of the $\mathrm{C}=\mathrm{O}$ bond of the carboxylate group in the apricot gum material. On the other hand, the peak at $1100 \mathrm{~cm}^{-1}$ confirms the presence of the $\mathrm{C}-\mathrm{O}$ bond, while the C-H bond presents at the peak of $2960 \mathrm{~cm}^{-1}[16]$.

3.2. Weight Loss Measurements. The corrosion of mild steel in $1 \mathrm{M} \mathrm{HCl}$ in the absence and presence of natural polymer (GA) as an inhibitor was investigated at a temperature range of 17$40^{\circ} \mathrm{C}$ applying the weight loss technique. Figure 2 shows the weight loss of metal with time (hours) in $1 \mathrm{M}$ hydrochloric acid devoid of and in the presence of GA $(0.1,0.2$, and $0.3 \mathrm{~g} / \mathrm{L}$ ) at 17,30 , and $40^{\circ} \mathrm{C}$ temperatures curing. The weight loss of mild steel reduces in the presence of the inhibitor in the hydrochloric acid solution as compared to the inhibitorfree solution, as shown in Figure 2. It was observed that the weight loss decreased with an increasing GA loading at temperatures of 30 and $40^{\circ} \mathrm{C}$ while it was constant with an increasing GA amount from 0.2 to $0.3 \mathrm{~g} / \mathrm{L}$ at the temperature of $17^{\circ} \mathrm{C}$ and this indicates that the inhibitor does not have an effect at this range of GA loading. The reason may be the no change in solubility of the GA at low temperature $\left(17^{\circ} \mathrm{C}\right)$ where the temperature is an important factor in the solubility of materials.

The corrosion rates and inhibition efficiency were estimated at the various concentrations of inhibitor and at various temperatures as shown in Table 2. The outcomes revealed that the $\mathrm{CR}$ was decreased with the loading of the GA inhibitor as compared to the case without loading 
TABLE 2: CR and inhibition efficiency (I\%) of mild steel in $1 \mathrm{M} \mathrm{HCl}$ for various inhibitor concentrations at various temperatures.

\begin{tabular}{|c|c|c|c|c|c|c|}
\hline \multirow{2}{*}{ System/concentration } & \multicolumn{3}{|c|}{$\mathrm{CR}\left(\mathrm{mg} / \mathrm{cm}^{2} \cdot \mathrm{h}\right)$} & \multicolumn{3}{|c|}{ Inhibition efficiency (I\%) } \\
\hline & $17^{\circ} \mathrm{C}$ & $30^{\circ} \mathrm{C}$ & $40^{\circ} \mathrm{C}$ & $17^{\circ} \mathrm{C}$ & $30^{\circ} \mathrm{C}$ & $40^{\circ} \mathrm{C}$ \\
\hline Blank & 5.744792 & 22.74479 & 43.625 & - & - & - \\
\hline $0.1 \mathrm{~g} / \mathrm{L}$ & 4.5 & 14.23438 & 16.49479 & 21.66818 & 37.41699 & 62.18959 \\
\hline $0.2 \mathrm{~g} / \mathrm{L}$ & 3.864583 & 13.30729 & 14.54688 & 32.72892 & 41.49302 & 66.65473 \\
\hline $0.3 \mathrm{~g} / \mathrm{L}$ & 3.791667 & 11.11979 & 11.51563 & 33.99819 & 51.1106 & 73.60315 \\
\hline
\end{tabular}

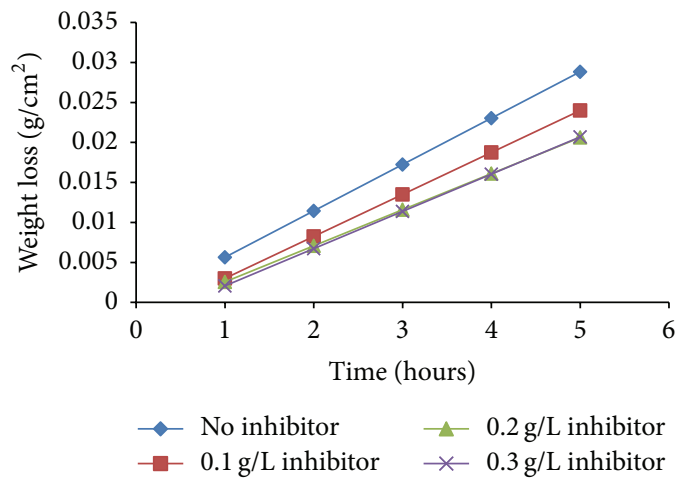

(a)

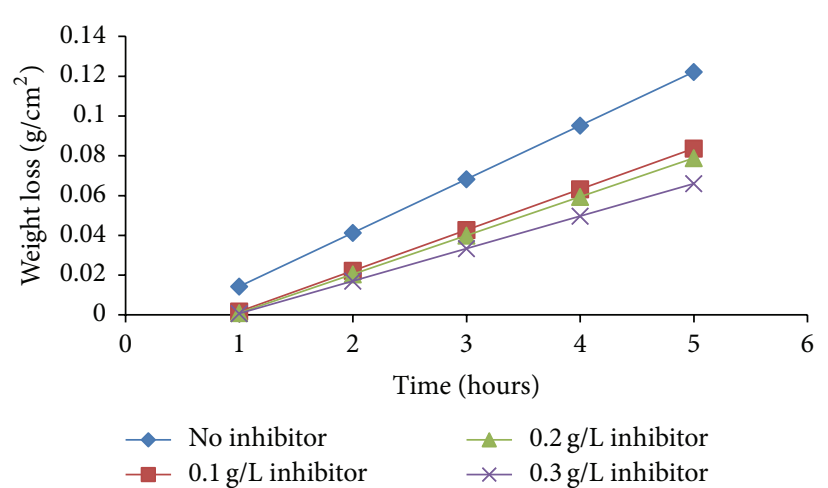

(b)

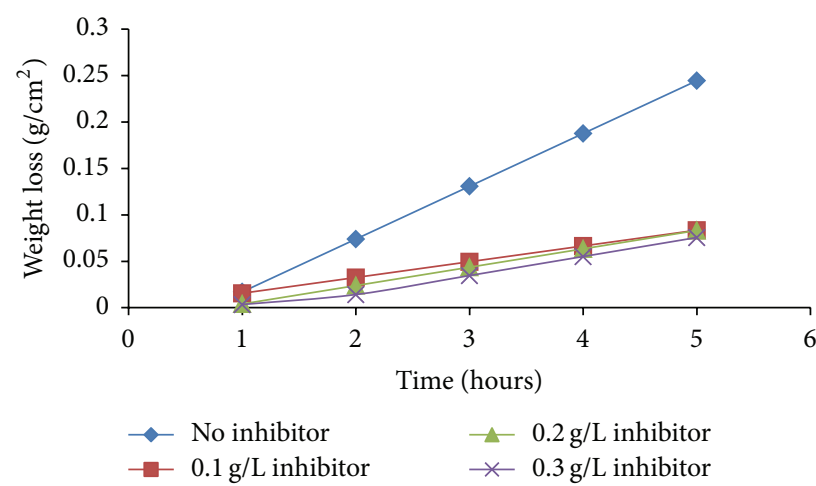

(c)

Figure 2: Weight loss of mild steel versus time (hours) in $1 \mathrm{M}$ hydrochloric acid in the absence and presence of natural polymer at (a) $17^{\circ} \mathrm{C}$, (b) $30^{\circ} \mathrm{C}$, and (c) $40^{\circ} \mathrm{C}$.

of the GA inhibitor in solution. Moreover, the corrosion rate was boosted with high temperature. In addition, the inhibition efficiency was boosted with the rise in inhibitor concentration to gain a maximum value at $0.3 \mathrm{~g} / \mathrm{L}$ GA at the whole temperature range of $17-40^{\circ} \mathrm{C}$, as shown in Figure 3.

The adsorption of natural polymer (GA) onto mild steel surfaces leads to coverage of the surfaces of mild steel which led to the inhibition of the mild steel corrosion and stopping of the corrosion process. GA has a complex structure and is a divaricated, balanced or a little acidic, complicated polysaccharide gained as a blended $\mathrm{Ca}, \mathrm{Mg}$, and $\mathrm{K}$ salt [17]. Meanwhile, FTIR results showed that GA has oxygen atoms which tend to adsorb to metal face by a couple of electrons of the $\mathrm{O}$ atom. It was also confirmed [17] that GA has 1,3-linked $\beta$-Dgalactopyranosyl and glucoproteins species. Therefore, these polar materials support the absorption of the GA on mild steel surface and the result is the hindrance of the corrosion process from taking place. It can be concluded that the natural polymer (GA) can inhibit corrosion of mild steel by forming compositions with mild steel.

3.3. Adsorption Isotherm. The physical adsorption and chemical adsorption are two main types of adsorption of organic compounds on the metal surface subject to the nature of the electronic structure of the metal, the media, and the inhibitor compositions. Figure 4 exhibits the results of the relationship between the inhibition efficiency $(I \%)$ and the inhibitor concentration $(C)$ of GA at various temperatures. The result of inhibition efficiency revealed that it is boosted with both the rising of inhibitor concentration and the rising of temperature. Growth in inhibition efficiency with the rise of both inhibitor concentration and temperature indicates that the adsorption process follows the chemical adsorption mechanism. 


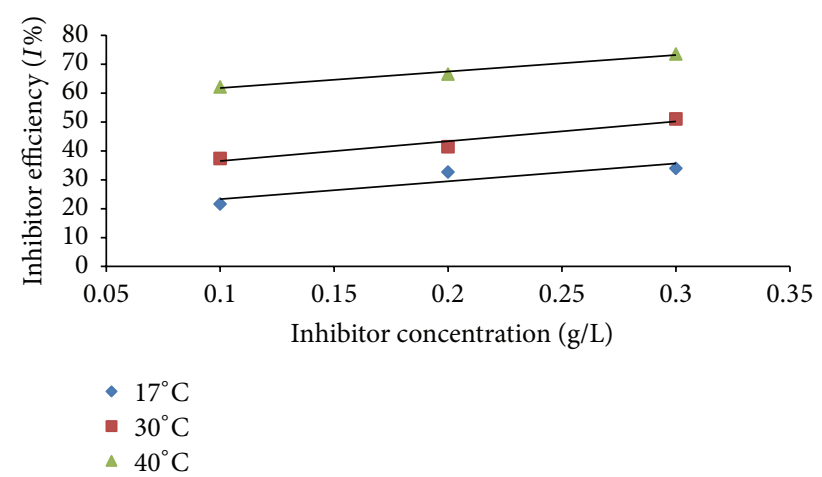

Figure 3: The inhibition efficiency (I\%) against inhibitor concentration for mild steel in $1 \mathrm{MHCl}$ containing $\mathrm{GA}$ at different temperatures.

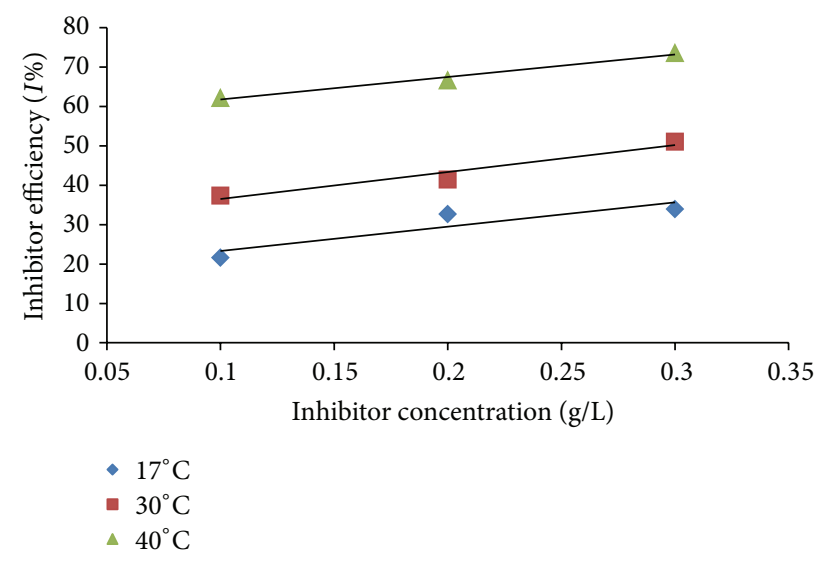

FIGURE 4: Inhibition efficiency of GA versus inhibitor concentration at various temperatures.

The surface coverage $(\theta)$ values explained the character of adsorption of GA. The surface coverage can be estimated by the following equation:

$$
\theta=\frac{I \%}{100} .
$$

$\theta$ amounts of the inhibitor have been utilized to demonstrate the best isotherm to locate the adsorption behavior. The adsorption isotherms of Frumkin [1], Temkin [18], FloryHuggin [7], Langmuir [19], and Freundlich [20] were fitted to $\theta$. The correlation coefficient $R^{2}$ was utilized to compare all these models to choose the best isotherm. It was observed that the best fit of $\theta$ was gotten with Temkin, Langmuir, and Freundlich adsorption isotherms.

The Temkin adsorption isotherm equation is

$$
\operatorname{Exp}(-2 a \theta)=K C,
$$

where " $a$ " is the heterogeneous factor of the metal surface describing the molecular interactions in the adsorption layer which is called lateral interaction parameter while $K$ is the equilibrium constant of the adsorption process. The surface coverage was plotted versus the logarithm of inhibitor concentration of GA at different temperatures (17, 30, and

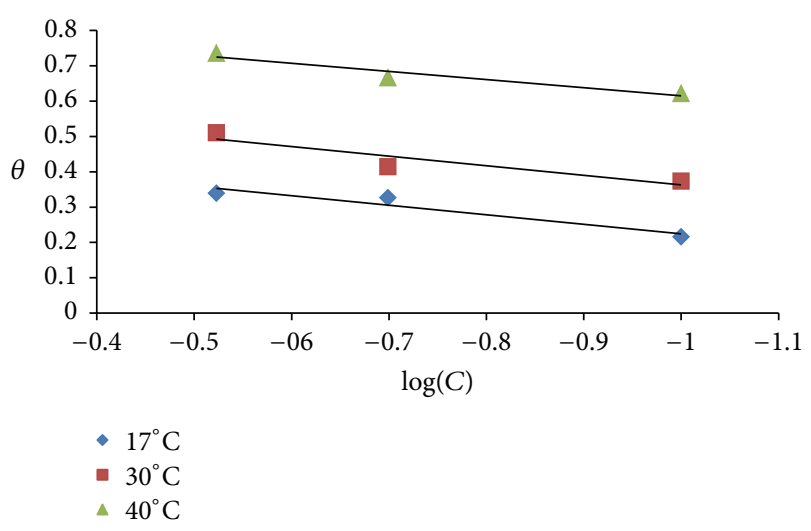

FIGURE 5: The surface coverage $(\theta)$ against the $\log$ of $C_{\mathrm{GA}}$ at various temperatures.

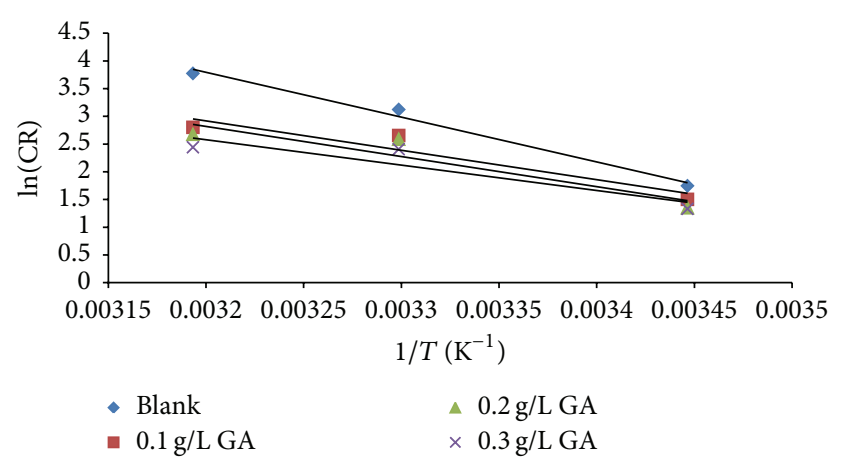

FIGURE 6: Logarithm of corrosion rate (CR) against inverse temperature for mild steel with and without GA in $1 \mathrm{M} \mathrm{HCl}$.

$40^{\circ} \mathrm{C}$ ), as shown in Figure 5. It was concluded from Figure 5 that the experimental data follow the Temkin adsorption isotherm as revealed by a linear relationship between the surface coverage and inhibitor concentration of GA in all ranges of temperatures.

The adsorption variables of Temkin adsorption isotherms are exhibited in Table 3 for mild steel corrosion in $1 \mathrm{M} \mathrm{HCl}$ in the presence of $\mathrm{GA}$ at 17,30 , and $40^{\circ} \mathrm{C}$. The attraction and repulsive forces between adsorbed molecules can be deduced by the plus and minus signs of the molecular interaction parameter amount (a), respectively [21]. As shown in Table 3, repulsion between the adsorbed molecules occurred because " $a$ " values were negative [22]. $K$ indicates the intensity between the adsorbate and adsorbent. Increased $K$ amounts displayed more efficient adsorption and thus better inhibition efficiency [23]. It can be suggested that chemical adsorption onto the metal face occurred because $K$ values increased with the increase in temperature.

3.4. Effect of Temperature. Corrosion of mild steel in $1 \mathrm{M} \mathrm{HCl}$ was investigated in the temperature range of $17-40^{\circ} \mathrm{C}$ with and without GA inhibitor. The results of the plotting logarithm of $\mathrm{CR}$ against different temperatures inverse are presented in Figure 6 for blank and GA inhibitor. The straight lines were gained to suggest that the relationship between the $\mathrm{CR}$ and temperature obeys the Arrhenius equation and 
TABLE 3: Temkin isotherm parameters at 17,30 , and $40^{\circ} \mathrm{C}$ for mild steel in $1 \mathrm{M} \mathrm{HCl}$ with GA.

\begin{tabular}{lccc}
\hline \multirow{2}{*}{ System/temperature } & \multicolumn{3}{c}{ Temkin adsorption isotherm } \\
& $a$ & $K$ & $R^{2}$ \\
\hline $17^{\circ} \mathrm{C}$ & -1.85048 & 6.239288 & 0.9142 \\
$30^{\circ} \mathrm{C}$ & -1.84706 & 10.39897 & 0.8874 \\
$40^{\circ} \mathrm{C}$ & -2.1796 & 39.73429 & 0.9379 \\
\hline
\end{tabular}

TABLE 4: The activation energy $(\mathrm{KJ} / \mathrm{mol})$, enthalpy $(\mathrm{KJ} / \mathrm{mol})$, and entropy $(\mathrm{J} / \mathrm{mol} \cdot \mathrm{K})$ of mild steel corrosion in $1 \mathrm{M} \mathrm{HCl}$ with $\mathrm{GA}$ inhibitor.

\begin{tabular}{lccc}
\hline System/concentration $E_{a}(\mathrm{KJ} / \mathrm{mol})$ & $\begin{array}{c}\Delta H_{\mathrm{ads}}^{o} \\
(\mathrm{KJ} / \mathrm{mol})\end{array}$ & $\begin{array}{c}\Delta S_{\mathrm{ads}}^{o} \\
(\mathrm{~J} / \mathrm{mol} \cdot \mathrm{K})\end{array}$ \\
\hline Blank & 67.286 & 64.783 & -6.43458 \\
$0.1 \mathrm{~g} / \mathrm{L}$ & 44.094 & 41.591 & -87.9367 \\
$0.2 \mathrm{~g} / \mathrm{L}$ & 45.218 & 42.716 & -85.1682 \\
$0.3 \mathrm{~g} / \mathrm{L}$ & 38.042 & 35.538 & -110.143 \\
\hline
\end{tabular}

the straight line slope represents activation energy. Arrhenius equation can be written as the following:

$$
\ln \mathrm{CR}=\ln A-\frac{E_{a}}{R T},
$$

where $\mathrm{CR}, A, E_{a}, R$, and $T$ are the corrosion rate, the Arrhenius constant, the activation energy, the molar gas constant, and the absolute temperature, respectively. Table 4 shows the activation energy $\left(E_{a}\right)$ values. The activation energy decreases with inhibitor loading as compared to the blank sample. It may be assigned to a perceivable boost in the inhibitor adsorption on the metal layer with an increase in temperature (chemisorption).

Enthalpy of adsorption, $\Delta H$, and entropy of adsorption, $\Delta S$, for the mild steel corrosion in $1 \mathrm{M} \mathrm{HCl}$ with GA inhibitor were gained by applying transition state equation [24] given by

$$
\mathrm{CR}=\frac{R T}{N h} \exp \left(\frac{\Delta S}{R}\right) \exp \left(-\frac{\Delta H}{R T}\right),
$$

where $N, h, R$, and $T$ are Avogadro's number, Planck's constant, molar gas constant, and the absolute temperature, respectively. The plot of the logarithm $(\mathrm{CR} / T)$ versus inverse temperature with and without inhibitor is presented in Figure 7. The enthalpy of adsorption and entropy of adsorption were acquired by the slope $(-\Delta H / R)$ and intercept of the lines, respectively, and the results were reported in Table 4 for the different concentrations $(0,0.1,0.2$, and $0.3 \mathrm{~g} / \mathrm{L})$. The results point out that the adsorption enthalpy reduces with inhibitor loading as compared to the blank solution, which confirms the suggestion of chemisorption's mechanism. It was observed that the entropy of adsorption with and without inhibitor has negative values in a range between -37.05 and $-63.28 \mathrm{~J} \mathrm{~mol}^{-1} \mathrm{~K}^{-1}$. The negative values are signaling to boost in the systems order [11].

The intercept of the line obtained from a plot of $\log I \%$ versus $\log C$ represents the free energy of adsorption $\left(\Delta G_{\mathrm{ads}}^{o}\right)$,

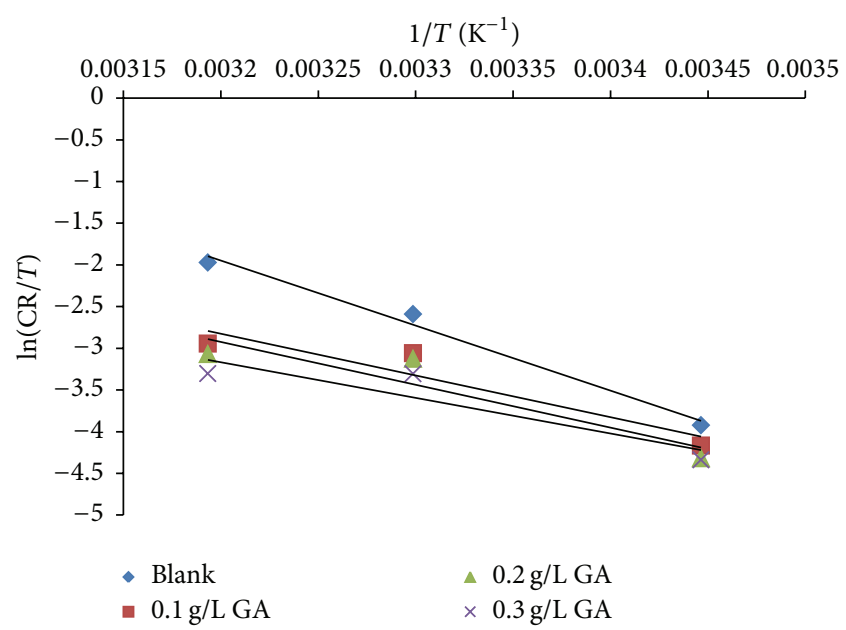

FIGURE 7: Transition state plot of the corrosion rate for mild steel in $1 \mathrm{M} \mathrm{HCl}$ with and without GA.

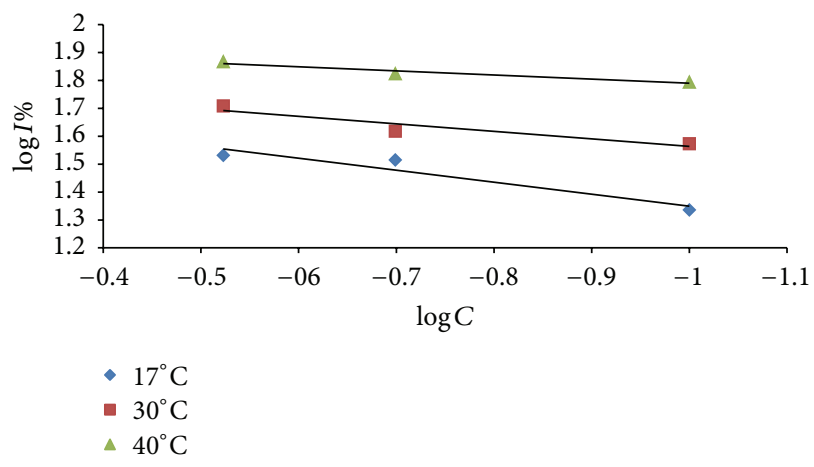

FIGURE 8: $\log I \%$ versus $\log C$ for mild steel corrosion in $1 \mathrm{M} \mathrm{HCl}$ for GA at 17,30 , and $40^{\circ} \mathrm{C}$.

as shown in Figure 8, according to the following equation [25]:

$$
\log C=\log \frac{\theta}{1-\theta}-\log B
$$

where

$$
\log B=-1.74-\left(\frac{\Delta G_{\mathrm{ads}}^{o}}{2.303 R T}\right) .
$$

The results of $\Delta G_{\text {ads }}^{o}$ at 17,30 , and $40^{\circ} \mathrm{C}$ are shown in Table 5. The free energy of adsorption values is negative, which refers to the spontaneous adsorption of the GA.

\section{Mechanism of Corrosion Inhibition}

The main factor for the efficiency of an organic compound to act as corrosion inhibitor (Inh) is its capacity to adsorb on a metal face to replace the water molecules by organic compound, as shown in the equilibrium equation below:

$$
\mathrm{Inh}_{(\text {sol })}+n \mathrm{H}_{2} \mathrm{O}_{(\mathrm{ads})} \longleftrightarrow \mathrm{Inh}_{(\mathrm{ads})}+n \mathrm{H}_{2} \mathrm{O}_{(\text {sol })}
$$

Many parameters control the inhibitor adsorption on the metal face, which include electronic structure, steric factor, 
TABLE 5: Gibbs free energy of mild steel corrosion in $1 \mathrm{M} \mathrm{HCl}$ with GA.

\begin{tabular}{lc}
\hline Temperature $\left({ }^{\circ} \mathrm{C}\right)$ & $\Delta G_{\mathrm{ads}}^{o}(\mathrm{KJ} / \mathrm{mol})$ \\
\hline 17 & -19.551 \\
30 & -19.848 \\
40 & -20.431 \\
\hline
\end{tabular}

the electronic density at the donor site, functional groups, and molecular size [26].

The complex chemical composition of GA contains 1,3linked $\beta$-D-galactopyranosyl units. Its branches consist of 2 to 5 molecules of 1,3-linked $\beta$-D-galactopyranosyl connected to the backbone of GA by 1,6-linkages. Both the branch and backbones of GA include units of $\alpha$-L-arabinofuranosyl, $\alpha$ L-rhamnosyl, $\beta$-D-glucuronopyranosyl, and 4-O-methyl- $\beta$ D-glucuronopyranosyl [17]. The inhibitor of apricot gum has an oxygen atom in its structure, as confirmed by FTIR result, which contains pairs of electrons. Therefore, it predicts that GA inhibitor with the long hydrocarbon chain adsorbs on the mild steel face due to the unoccupied $d$-orbital of iron atoms to cover large surface area of mild steel.

The anodic and cathodic reactions are consistent of $\mathrm{Fe}^{2+}$ and $\mathrm{OH}^{-}$, respectively [27]:

$$
\mathrm{Fe} \longrightarrow \mathrm{Fe}^{2+}+2 \mathrm{e}^{-}
$$

(anodic reaction)

$$
2 \mathrm{H}_{2} \mathrm{O}+\mathrm{O}_{2}+4 \mathrm{e}^{-} \longrightarrow 4 \mathrm{OH}^{-} \quad \text { (cathodic reaction) }
$$

The inhibition of anodic reaction on the metal surface is done by the consistence of $\mathrm{Fe}^{2}$-GA complex on the anodic positions of the mild steel surface while the inhibition of cathodic reaction is done by the cohesion of insoluble material which is formed by hydroxide on the cathodic positions of the metal complex [27].

\section{Conclusion}

The corrosion of mild steel in $1 \mathrm{M} \mathrm{HCl}$ with and without natural polymer as inhibitor was investigated using the weight loss technique at a temperature range of $17-40^{\circ} \mathrm{C}$. The spectrum of FTIR shows clearly that natural polymer structure has $\mathrm{C}=\mathrm{O}$ and $\mathrm{O}-\mathrm{H}$ groups which lead to improving the adhesion of natural polymer on iron metal. The weight loss of mild steel reduces the loading of the inhibitor to the acid solution as compared to the blank. Meanwhile, the temperature is an important factor in the solubility of materials; therefore, the natural polymer has no effect on weight loss of mild steel at the temperature of $17^{\circ} \mathrm{C}$. It was proposed that the adsorption of natural polymer onto mild steel surface was a chemical adsorption mechanism. Temkin, Langmuir, and Freundlich adsorption isotherms are the best fit of adsorption isotherms. The activation energy and enthalpy of adsorption decrease in the presence of the natural polymer as compared to the blank. The negative values of adsorption entropy revealed an increase in the systems order.

\section{Competing Interests}

The authors declare that they have no competing interests.

\section{References}

[1] A. S. Fouda and M. M. Mukhtar, "New arylazodyes as corrosion inhibitors for mild steel in HCL solution," Chemical Engineering Communications, vol. 198, no. 9, pp. 1111-1128, 2011.

[2] X. Li, S. Deng, H. Fu, and T. Li, "Adsorption and inhibition effect of 6-benzylaminopurine on cold rolled steel in 1.0 M HCl," Electrochimica Acta, vol. 54, no. 16, pp. 4089-4098, 2009.

[3] S. Gowri, J. Sathiyabama, and S. Rajendran, "Corrosion inhibition effect of carbon steel in sea water by L-arginine- $\mathrm{Zn}^{2+}$ system," International Journal of Chemical Engineering, vol. 2014, Article ID 607209, 9 pages, 2014.

[4] S. K. Shukla, M. A. Quraishi, and R. Prakash, "A self-doped conducting polymer 'polyanthranilic acid': an efficient corrosion inhibitor for mild steel in acidic solution," Corrosion Science, vol. 50, no. 10, pp. 2867-2872, 2008.

[5] E. A. Noor, "Evaluation of inhibitive action of some quaternary $\mathrm{N}$-heterocyclic compounds on the corrosion of $\mathrm{Al}-\mathrm{Cu}$ alloy in hydrochloric acid," Materials Chemistry and Physics, vol. 114, no. 2-3, pp. 533-541, 2009.

[6] I. Ahamad and M. A. Quraishi, "Mebendazole: new and efficient corrosion inhibitor for mild steel in acid medium," Corrosion Science, vol. 52, no. 2, pp. 651-656, 2010.

[7] E. E. Oguzie, C. O. Akalezi, C. K. Enenebeaku, and J. N. Aneke, "Corrosion inhibition and adsorption behavior of malachite green dye on aluminum corrosion," Chemical Engineering Communications, vol. 198, no. 1, pp. 46-60, 2011.

[8] A. Y. El-Etre, "Natural honey as corrosion inhibitor for metals and alloys. I. Copper in neutral aqueous solution," Corrosion Science, vol. 40, no. 11, pp. 1845-1850, 1998.

[9] A. Y. El-Etre and M. Abdallah, "Natural honey as corrosion inhibitor for metals and alloys. II. C-steel in high saline water," Corrosion Science, vol. 42, no. 4, pp. 731-738, 2000.

[10] A. Ostovari, S. M. Hoseinieh, M. Peikari, S. R. Shadizadeh, and S. J. Hashemi, "Corrosion inhibition of mild steel in $1 \mathrm{M}$ $\mathrm{HCl}$ solution by henna extract: a comparative study of the inhibition by henna and its constituents (Lawsone, Gallic acid, $\alpha$-d-Glucose and Tannic acid)," Corrosion Science, vol. 51, no. 9, pp. 1935-1949, 2009.

[11] A. Y. El-Etre, "Inhibition of aluminum corrosion using Opuntia extract," Corrosion Science, vol. 45, no. 11, pp. 2485-2495, 2003.

[12] M. Abdallah, "Guar gum as corrosion inhibitor for carbon steel in sulfuric acid solutions," Portugaliae Electrochimica Acta, vol. 22, no. 2, pp. 161-175, 2004.

[13] A. Chetouani, B. Hammouti, and M. Benkaddour, "Corrosion inhibition of iron in hydrochloric acid solution by jojoba oil," Pigment and Resin Technology, vol. 33, no. 1, pp. 26-31, 2004.

[14] A. Bouyanzer and B. Hammouti, "A study of anti-corrosive effects of Artemisia oil on steel," Pigment \& Resin Technology, vol. 33, no. 5, pp. 287-292, 2004.

[15] E. E. Oguzie, "Inhibition of acid corrosion of mild steel by Telfaria occidentalis extract," Pigment and Resin Technology, vol. 34, no. 6, pp. 321-326, 2005.

[16] S. S. Banerjee and D.-H. Chen, "Fast removal of copper ions by gum arabic modified magnetic nano-adsorbent," Journal of Hazardous Materials, vol. 147, no. 3, pp. 792-799, 2007. 
[17] D. Verbeken, S. Dierckx, and K. Dewettinck, "Exudate gums: occurrence, production, and applications," Applied Microbiology and Biotechnology, vol. 63, no. 1, pp. 10-21, 2003.

[18] P. C. Okafor and Y. Zheng, "Synergistic inhibition behaviour of methylbenzyl quaternary imidazoline derivative and iodide ions on mild steel in $\mathrm{H}_{2} \mathrm{SO}_{4}$ solutions," Corrosion Science, vol. 51, no. 4, pp. 850-859, 2009.

[19] F. A. Ansari and M. A. Quraishi, "Prevention of metallic corrosion by thiocarbohydrazides and their salts in vapor phase environment," Chemical Engineering Communications, vol. 198, no. 1, pp. 61-72, 2010.

[20] I. O. Arukalam, I. C. Madufor, O. Ogbobe, and E. E. Oguzie, "Inhibition of mild steel corrosion in sulfuric acid medium by hydroxyethyl cellulose," Chemical Engineering Communications, vol. 202, no. 1, pp. 112-122, 2015.

[21] E. A. Noor, "Temperature effects on the corrosion inhibition of mild steel in acidic solutions by aqueous extract of fenugreek leaves," International Journal of Electrochemical Science, vol. 2, no. 12, pp. 996-1017, 2007.

[22] L. Tang, X. Li, Y. Si, G. Mu, and G. Liu, "The synergistic inhibition between 8-hydroxyquinoline and chloride ion for the corrosion of cold rolled steel in $0.5 \mathrm{M}$ sulfuric acid," Materials Chemistry and Physics, vol. 95, no. 1, pp. 29-38, 2006.

[23] S. A. M. Refaey, F. Taha, and A. M. A. El-Malak, "Inhibition of stainless steel pitting corrosion in acidic medium by 2-mercaptobenzoxazole," Applied Surface Science, vol. 236, no. 1, pp. 175185, 2004.

[24] I. M. Alwaan, "Kinetics of thermal degradation of recycled polyvinyl chloride resin," International Journal of Chemical Engineering, vol. 2014, Article ID 701092, 7 pages, 2014.

[25] S. Bilgiç and M. Şahin, "The corrosion inhibition of austenitic chromium-nickel steel in $\mathrm{H}_{2} \mathrm{SO}_{4}$ by 2-butyn-1-ol," Materials Chemistry and Physics, vol. 70, no. 3, pp. 290-295, 2001.

[26] M. Yadav, D. Behera, S. Kumar, and P. Yadav, "Experimental and quantum chemical studies on corrosion inhibition performance of thiazolidinedione derivatives for mild steel in hydrochloric acid solution," Chemical Engineering Communications, vol. 202, no. 3, pp. 303-315, 2015.

[27] N. Saxena, S. Kumar, and S. P. Mathur, "Anisalidine derivatives as corrosion inhibitors of mild steel in acidic media. 1," Chemical Engineering Communications, vol. 196, no. 12, pp. 1451-1465, 2009. 


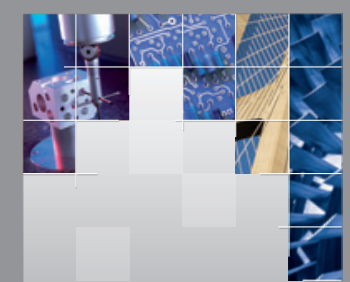

\section{Enfincering}
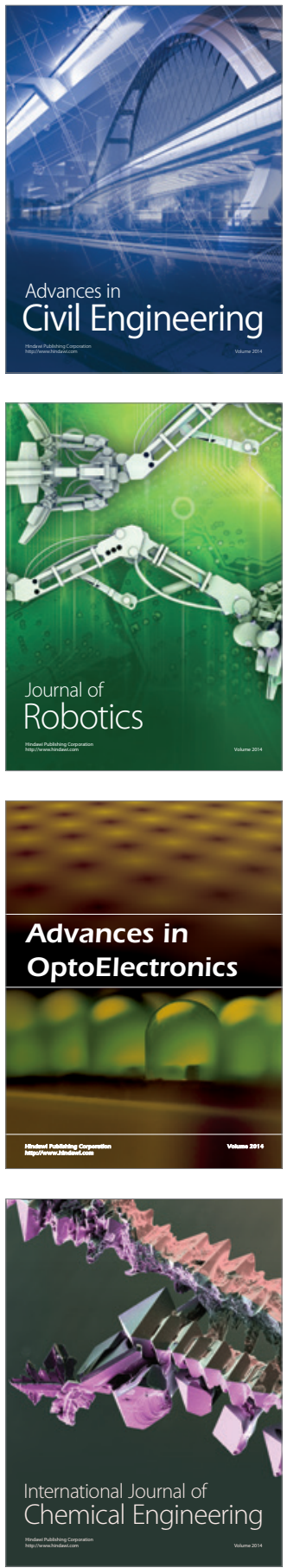

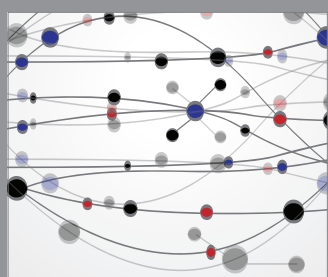

The Scientific World Journal

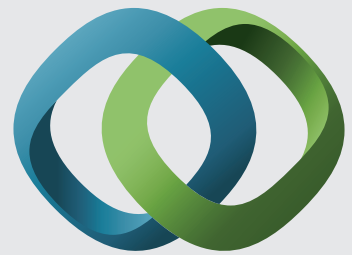

\section{Hindawi}

Submit your manuscripts at

http://www.hindawi.com
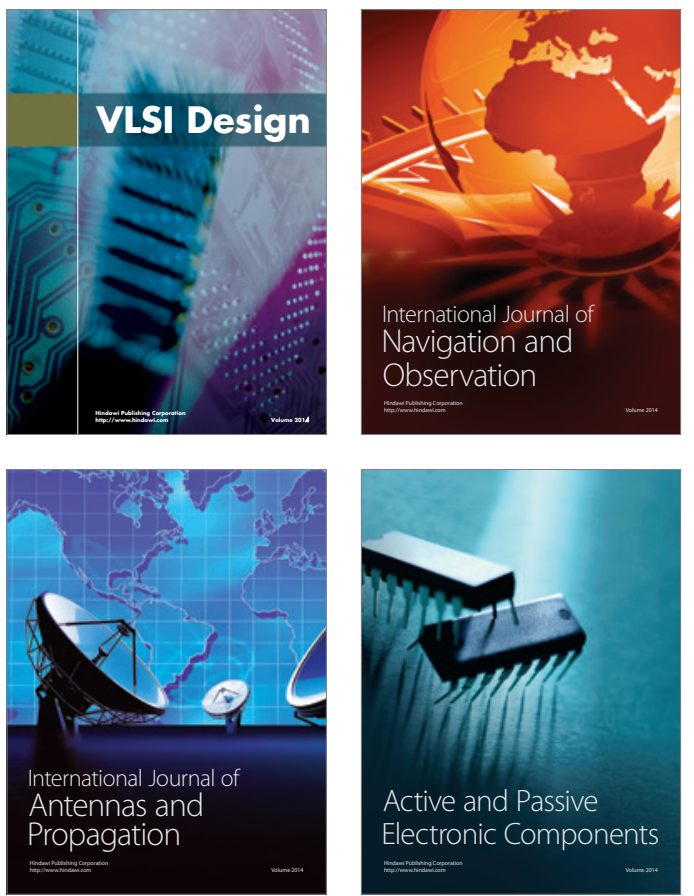
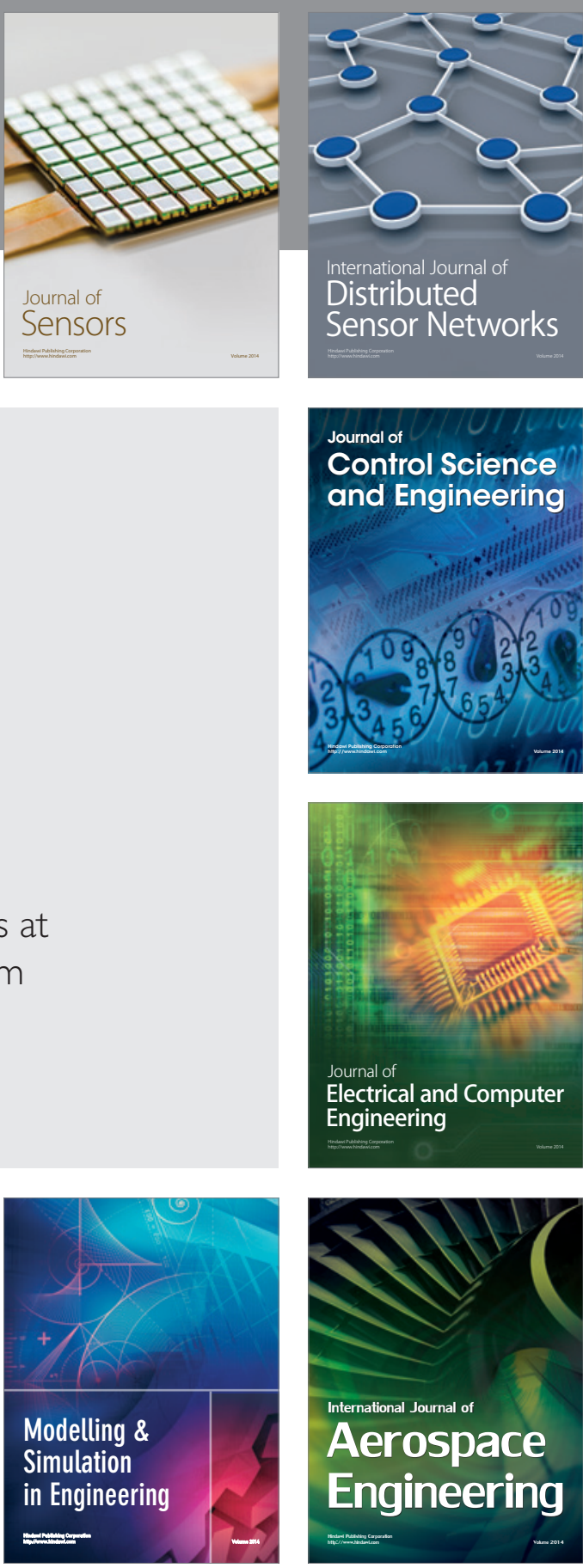

International Journal of

Distributed

Sensor Networks

Journal of

Control Science

and Engineering
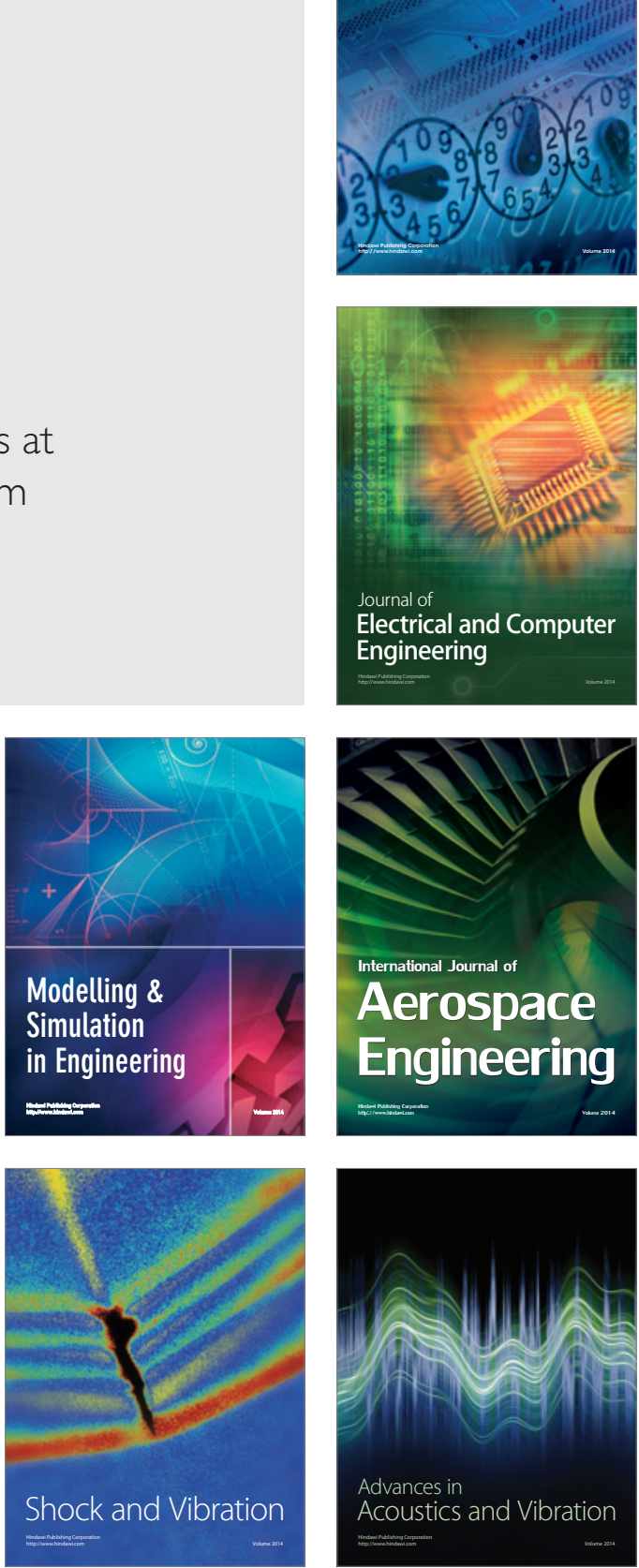